\title{
Lung Herniation: An Unusual Cause of Chest Pain
}

\author{
Max L. Cohen MD PhD \\ Sumugdha Rayamajhi MD \\ Jonathan S. Kurche MD PhD \\ Carolyn H. Welsh MD \\ Denver VA Medical Center \\ University of Colorado Denver \\ Denver, CO
}

\begin{abstract}
We report a morbidly obese 72-year-old man admitted with acute right-sided chest pain and hypoxemia following bouts of vigorous coughing. This case illustrates the need to consider unusual etiologies of a common clinical presentation.
\end{abstract}

\section{Case Presentation}

History of Present IIIness

A 72-year-old morbidly obese male presented with a feeling of tearing chest pain radiating to the right flank following repeated bouts of vigorous coughing. He was unable to take in a deep breath or lie flat and developed an abdominal bruise shortly after the tearing pain. He denied fever, dizziness or change in his baseline clear phlegm.

His medical history included GOLD I chronic obstructive pulmonary disease for which he used daily inhaled budesonide/formoterol, as-needed inhaled albuterol/ipratropium, and supplemental oxygen with exertion at 3 liters per minute. One year prior to admission, his FEV1/FVC ratio was 0.69 with air trapping and diffusion capacity $79 \%$ predicted. He had severe obstructive sleep apnea with an apnea hypopnea index of 52 for which he used home bi-level positive pressure at night at $25 / 14 \mathrm{~cm}$ water (IPAP/EPAP) with supplemental oxygen at 2 liters per minute. He had not recently received systemic corticosteroids; his last course was 5 months prior to admission.

Past Medical History

He had hypertension, hypothyroidism, gout, an umbilical hernia, hyperlipidemia, diverticulosis, and a peripheral neuropathy due to Agent Orange exposure.

Past surgical history included a remote uvulopalatopharyngoplasty (UPPP) for his sleep apnea. Three years previously he fell from a motor scooter and was hospitalized with four fractured left ribs.

He drank alcohol frequently until several months prior to admission. 


\section{Physical Examination}

Vital signs on presentation were significant for a heart rate of 110 , a respiratory rate of 22, and hypoxia with an $\mathrm{O}_{2}$ saturation of $88 \%$ on room air. His BMI was $52 \mathrm{~kg} / \mathrm{m}^{2}$. Breath sounds were distant and diminished on the right side. He had extensive ecchymosis extending from the right flank to the periumbilicum, and a tender right chest wall in the lower mid-clavicular region. He had a large umbilical hernia that was easily reduced. His legs showed 3+ edema to the thighs.

\section{Laboratory findings}

He had a white blood cell count of 11,300/ul, a hemoglobin of $10.9 \mathrm{~g} / \mathrm{dL}$, and a platelet count of 319,000/ul. He had a normal creatinine, electrolytes, and a negative troponin. The proBNP was $449 \mathrm{pg} / \mathrm{ml}$.

\section{Radiography}

Admission roentography and computed tomography of the chest with contrast (not shown) initially revealed hyperinflated lungs, a small loculated pleural effusion, a chest wall hematoma on the right, and no pulmonary thromboembolus.

\section{Hospital Course}

Bi-level positive pressure non-invasive ventilation (PAP) was resumed with his normal home settings of 25/14 cm water. Supplemental oxygen was administered, and a combination of opiates and NSAIDs were used for pain control. He remained hypoxic, with a persistent cough, and worsening pain. The character of the pain changed from tearing to pleuritic. Repeat computed tomography of the chest prompted by persistent pain revealed herniation of lung parenchyma through the $8^{\text {th }}$ and $9^{\text {th }}$ rib to the extrathoracic space (Figures 1 ).
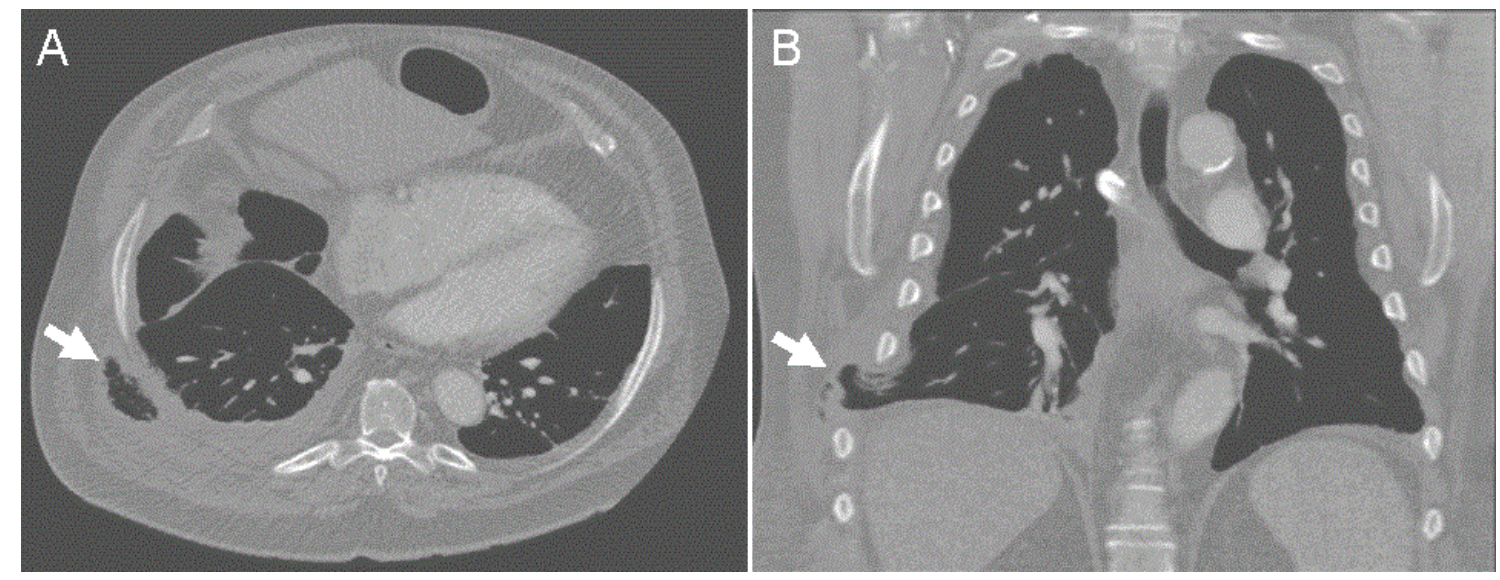

Figure 1. Panel A: Repeat CT scan with axial reconstruction demonstrating extrathoracic presence of lung parenchyma (arrow). Panel B: Repeat CT scan with coronal reconstruction demonstrating herniation of lung parenchyme through the $8^{\text {th }}-9^{\text {th }}$ intercostal space (arrow). 
A palpable subcutaneous mass was not present at any point during his hospitalization. The cardiothoracic surgery service was consulted for possible intervention. Given the non-incarcerated nature of hernia and presence of multiple comorbidities, a decision was made to conservatively manage and follow with repeated thoracic imaging. His pain and hypoxemia gradually improved.

Six months after presentation, lung herniation was still visible on roentography (Figure 2) but he had minimal residual pain.

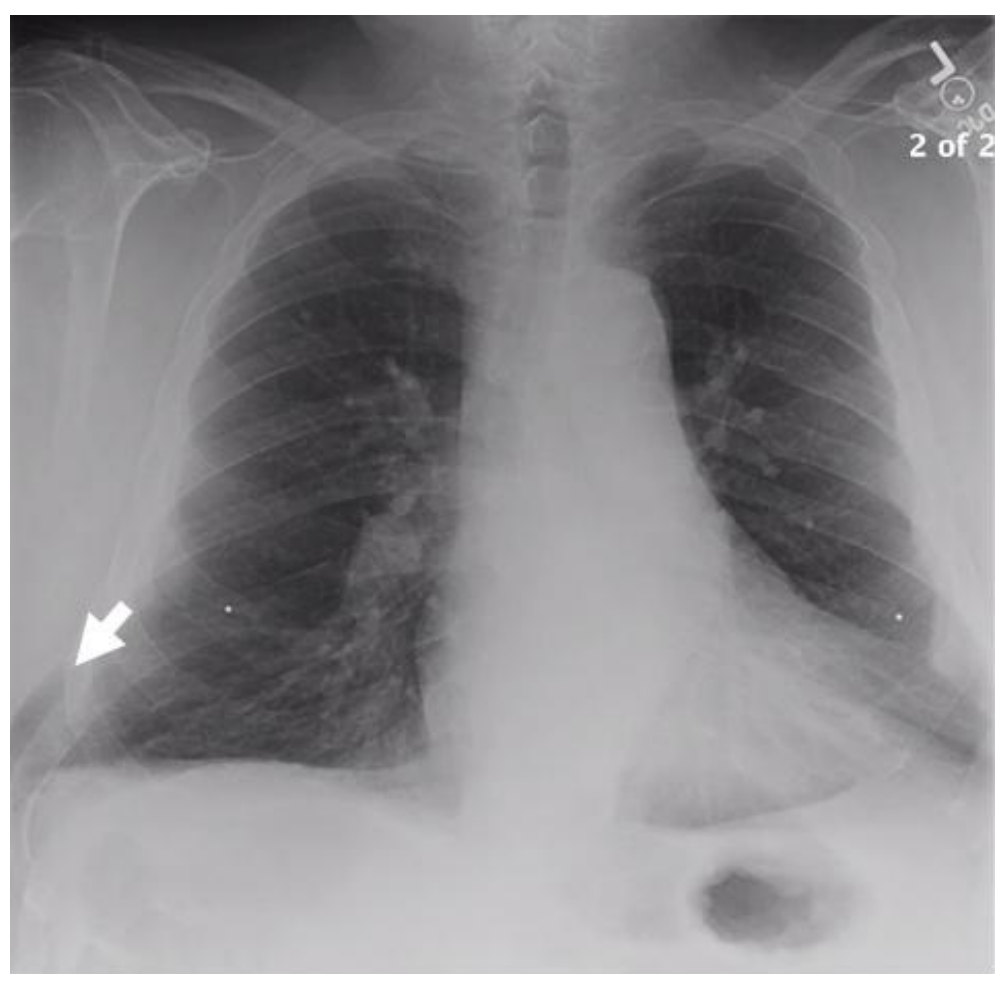

Figure 2. PA chest film 6 months after initial presentation showing persistence of herniated lung (arrow).

Due to the lack of symptoms, no surgical intervention was recommended.

\section{Discussion}

Pulmonary herniation is rare. By definition, it is the protrusion of lung tissue and pleural membranes beyond the confines of thoracic cavity, and is classified as cervical, thoracic, diaphragmatic or mediastinal depending on its anatomic location (1). Etiology-based classification divides it as congenital or acquired; while congenital hernias are typically found early in life, they can present in adults (2). Congenital hernias are associated with costal or cartilage malformation, whereas acquired hernias involve intercostal muscle weakness, 
especially with conditions that cause increases in intrathoracic pressure such as coughing (3), heavy weight lifting, profound obesity, or positive-pressure ventilation (including by non-invasive methods) (1-4). Other precipitating factors can include trauma, surgery, chronic obstructive pulmonary disease, asthma, chronic steroid use, inflammatory or neoplastic process (1-5). Our patient had many of the known above-mentioned risk factors and developed spontaneous traumatic herniation, likely due to vigorous coughing that led to an intercostal muscle tear. While rare, lung herniation should be considered in a patient with risk factors and chest pain, dyspnea, or hypoxemia without a clear cause.

\section{References}

1. Detorakis E, Androulidakis E. Intercostal lung herniation--the role of imaging. J Radiol Case Rep. 2014;1(8):16-24. [CrossRef] [PubMed]

2. Weissberg $D$, Refaely $Y$. Hernia of the lung. Ann Thorac Surg. 2002;74(6):1963-6. [CrossRef] [PubMed]

3. O'Shea M, Cleasby M. Lung herniation after cough-induced rupture of intercostal muscle. N Engl J Med. 2012;366(1):74. [CrossRef] [PubMed]

4. Sulaiman A, Cottin V, De Souza Neto EP, Orsini A, Cordier JF, Gamondes JP, Tronc F. Cough-induced intercostal lung herniation requiring surgery: Report of a case. Surg Today. 2006;36(11):978-80. [CrossRefl [PubMed]

5. Cafarotti S, Matarelli E, Guerra A, Dutly A. Large intercostal pulmonary hernia secondary to limited-access aortic valve surgery: video-assisted thoracoscopic technique repair. Lung. 2013;192(2):333-4. [CrossRef] [PubMed] 